\section{Administrative Classification of Australian Aborigines}

A NEw policy for the control of the aborigines under the jurisdiction of the Federal Government of the Commonwealth of Australia is announced by $\mathbf{M r}$. Paterson, Minister for the Interior (The Times, Oct. 4). These aborigines, that is, the inhabitants of the Northern Territories only, are estimated to number approximately 20,000 out of a total aboriginal population of 76,000 , of whom 22,000 are half-castes. In future they will be classified in three divisions : (1) detribalized natives, such as those near Darwin and other northern towns; (2) tribes on or near pastoral stations and other white settlements; and (3) aborigines beyond civilized control. This classification corresponds broadly with the facts, and will involve no very drastic interference with existing conditions. At the same time, official recognition and acceptance of a very real distinction should facilitate discrimination and increase efficiency in administering and applying any ameliorative policy. The disposition of the aborigines proposed under the new regulations is that the completely detribalized aborigines should be educated to a white standard, with the view of training them to become economically and occupationally efficient. Areas are to be set aside at Darwin, on which they will be encouraged to abandon their nomadic habits and to settle in family houses, cultivating the soil and rearing domestic animals. Barracks, schools and recreational and sanitary facilities will be provided. Semidetribalized natives will be settled in reserves, in which they will be enabled to live in native fashion; and myalis, aborigines completely under tribal institutions, will live in the inviolable reserves. The Australian aboriginal has shown himself singularly adaptable to the advantages of white civilization; but it will be interesting to watch how far this experiment in checking so deeply engrained a tribal habit as nomadism meets with success.

\section{Public Lighting}

In his address at the opening meeting of the Illuminating Engineering Society on October 13, the president, Mr. Arthur Cunnington, referred to several questions of outstanding interest in connexion with lighting, such as the need for greater uniformity in conditions of supply of gas and electricity, the desirability of designing fittings that are easy to maintain as well as efficient, and the effect of surroundings on conditions of illumination. In this connexion, he suggested that if owners of buildings would make a practice of steam-cleaning the surfaces of buildings before the period of the Coronation, this would not only improve the appearance of the streets but would also greatly facilitate floodlighting. The concluding section of the address emphasized the value to large consumers of trained lighting engineers who could form an impartial opinion of the merit of different systems and appliances. The need for expert public lighting engineers in large towns and cities has recently been emphasized, but there are many other bodies such as Government departments, railways and docks and large industrial concerns which could benefit from their services.

\section{Progress in Illumination}

IN accordance with the usual practice of the Illuminating Engineering Society at its opening meeting, a report on progress prepared by the Technical Committee and summarizing advances in lighting and photometry during the past year was presented, and a series of exhibits was arranged. Among the most striking of these was a new form of small electric discharge lamp (80 watt and 125 watt), produced by leading manufacturers in Great Britain. This lamp, which resembles in size and shape an ordinary filament lamp, is the first of the kind capable of being applied (with only a choke in circuit) on circuits of 200-250 volts (A.C.) for domestic and office use. These lamps have an initial efficiency of 40 lumens per watt and an average efficiency of 30 lumens per watt during life. Of considerable interest also were the demonstrations of the effect of bulbs coated with fluorescent powder, whereby the natural spectrum of the light can be considerably improved, and of various stroboscopic effects. Other exhibits included a model illuminated aerodrome and a model stage, improved forms of catalytic methods of ignition for gas burners, and a method of studying the brightness of illuminated roadways by the aid of accurate photographs taken by artificial light.

\section{The Microscope in Engineering and Industry}

THIs was the subject chosen by Mr. A. E. Bingham for the address with which, as chairman, he opened the session of the Junior Institution of Engineers on October 9. After explaining the lens system of the modern instrument, he gave a resume of its history and evolution to its present capacity for the production of photomicrographs of metallic surfaces with great clearness at high magnifications. In the majority of engineering investigations, the specimens under examination are opaque, and the difficulties of illumination and the most advantageous methods to use were discussed, as also were the preparation of metallic specimens and the making of photomicrographs. The petrological microscope, as used for the magnification of rock sections of less than one thousandth of an inch in thickness, and for their examination under polarized light, was also introduced. Many examples of the applications of microscopy were given, among them the examination and measurement of particles of abrasive powders, determination of the lengths of fibres used in the paper, artificial sillk and other industries, checking the results of heat treatment of steel, hardness testing, and the examination of profiles of screws, wheel teeth, and small products by means of the profile projector.

\section{Alcoholism and Psychiatry}

THE seventeenth Norman Kerr Memorial Lecture before the Society for the Study of Inebriety was delivered by Dr. D. K. Henderson, professor of psychiatry at the University of Edinburgh and physician superintendent of the Royal Edinburgh Hospital for Mental Diseases, on October 13, the subject being alcoholism and psychiatry. At the 